\title{
ANALYSIS OF RESPONSE AND RECOVERY OF VEGETATION TO FOREST FIRE
}

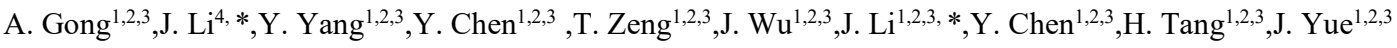 \\ ${ }^{1}$ State Key Laboratory of Remote Sensing Science, Beijing Normal University, Beijing, 100875, China \\ ${ }^{2}$ Beijing Key Laboratory of Environmental Remote Sensing and Digital City, Beijing Normal University, Beijing, 100875, China \\ ${ }^{3}$ Faculty of Geographical Science, Beijing Normal University, Beijing, 100875, China \\ ${ }^{4}$ Institute of geographic sciences and natural resources research,Beijing,100101, China- jingli_2022@outlook.com
}

\section{Commission III, WG III-IVa}

KEY WORDS: Forest fire, Vegetation changes, Vegetation restoration, GLASS

\begin{abstract}
:
To analyse the response and recovery characteristics of forest to forest fire, this paper selected the forest fire in the Greater Khingan Mountains (GKM) in China in 1987 and the forest fire in the Yellowstone National Park (YSP) in the United States in 1988. We first used Landsat- 5 TM images before and after the fire to extract the burned area and calculate burn severity based on the Differential Normalized Burn Ratio (dNBR). Next, we analysed the response of forest vegetation to forest fire with different burn severity using the anomaly value of Leaf area index (LAI) derived from Global Land Surface Satellite (GLASS) products. And the recovery of forest vegetation after forest fire were revealed using time - series LAI data and MODIS Land cover data. The results showed that the LAI decreased rapidly after the forest fire, and the greater the burn severity, the higher the decreasing amplitude of LAI. The maximum decreasing amplitude of LAI in the burned areas with high burn severity were 1.3 - 3.8 times higher than that in low burn severity areas. The recovery time of LAI is affected by burn severity and manual interference. The recovery time of LAI in burned areas in the GKM is about 5 - 10 years, which in the burned areas with high burn severity is 2 times than that with low burn severity. The recovery time of LAI in the burned areas with low burn severity in the YSP is at least 20 years, while that with high burn severity will take longer time to recovery. And the manual interference accelerated the recovery of LAI in the GKM. Our research on the response and recovery of vegetation is helpful for formulating and implementing adaptation and mitigation strategies in response to forest fire.
\end{abstract}

\section{INTRODUCTION}

At present, the occurrence of forest wildfires around the world is over 200 thousand each year, with burned areas of $3.5-4.5$ million $\mathrm{km} 2$ (Shi 2015). As a natural process, forest fires poses a serious threat to national economic development, global ecological system, personal safety (Houghton 1989), and ecosystem structure. Remote sensing data can accurately and permanently monitor the temporal and spatial information of forest fires, the evolution process (Jchoku 2012, García-Haro 2001) and the changes of vegetation affected by forest fires (Wang 2008, Hernandez 2009, Gp 2003), which has been widely used in recent years. At present, there are two main methods of the study of vegetation damage and recovery affected by forest fire: ground investigation and vegetation indices monitoring method. The ground investigation after the fire can provide a scientific basis for the recovery policies. A number of studies have studied the influencing factors of the recovery of vegetation after fire based on ground investigation (Cai 2012, Wang 2003). F. J. Xie et al's study found that the altitude was the most important factor that affected the restoration of the forest the GKM (Xie 2015). W. H. Cai et al investigated the succession of forest vegetation with different vegetation site conditions and vegetation types (Cai 2012). X. G. Wang et al found that the restoration and the effect of artificial intervention in the burned area with different burn severity was different (Wang 2003). This method cannot monitor the vegetation dynamics at high temporal resolution in the long term. Vegetation indices monitoring method can not only efficiently detect vegetation degradation in the early stage after fire, but also can observe the vegetation succession in burned area for a long time. Q. L Miao and F. J. Xie analysed the recovery of forest vegetation with different burn severity and vegetation types using time - series NDVI data (Miao 2015, Xie 2005). M. Z. Li analysed the effect of forest fire on vegetation indices in the GKM (Li 2015). Masek evaluated the disturbance of forest using muti-temporal NDVI data. Xiao X. M. analysed the disturbance of forest fire to forest vegetation using different vegetation indices like LAI, NDVI, EVI and LAWI (Xiao 2011). However, there is no comparability between the different studies because the algorithms of vegetation indices are different.

The forest canopy loss resulted from forest fires and forest recovery are usually characterized by leaf area index (LAI) or other vegetation indices that can reflect canopy photosynthetic capacity (Xiao 2011). GLASS - LAI products have longer time scales, bigger spacial extent and higher precision compared to the existing LAI products in the world (Liang2014). Currently, some scholars have used GLASS LAI products to monitor the forest disturbances in the GKM in northeastern China (Wang 2017) and have demonstrated the feasibility of LAI data in 
monitoring the vegetation of Amazonian rain forest (Liang 2016). Therefore, the use of GLASS - LAI product can more accurately reflect the changes of vegetation and conducive to the comparative analysis of different studies. This paper investigated vegetation response and recovery to forest fires based on GLASS - LAI product comprising 8-day data from 1982 to 2016.

\section{MATERIALS AND METHODS}

\subsection{Study Area}

\subsection{1 the Greater Khingan Mountains (GKM)}

A large forest fire occurred in the northern the GKM area, Heilongiiang Province, China (Figure 1) from May 6 to June 2, 1987. The GKM is the largest forest area in China $\left(121^{\circ} 12^{\prime} \mathrm{E}-\right.$ $127^{\circ} 00^{\prime} \mathrm{E}, 50^{\circ} 10^{\prime} \mathrm{E}-53^{\circ} 33^{\prime} \mathrm{E}$ ), Forest is the dominant vegetation types in the region, which occupies $81.23 \%$ of the total area. The region is characterized by a temperate continental monsoon climate, with annual average temperature of $-2^{\circ} \mathrm{C}$, annual rainfall of $429-527 \mathrm{~mm}$ and annual potential evaporation of $900-1000 \mathrm{~mm}$ (Forestry Administration, the GKM). The forest fires occur frequently in spring and autumn in the northern the GKM area.

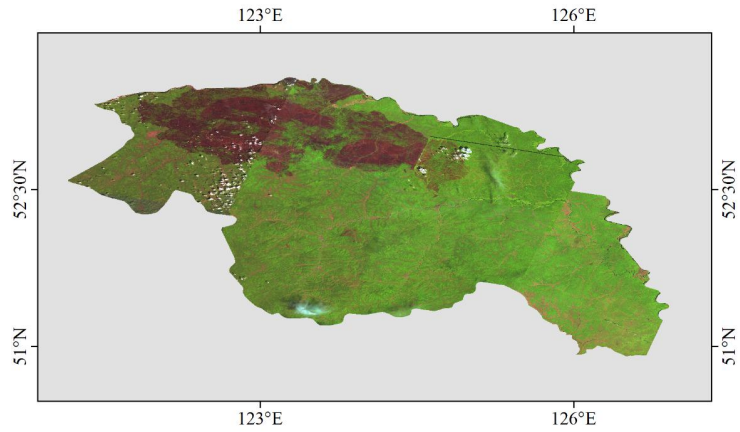

Figure 1: Study image of post-fire in the Greater khingan mountains. False color (Green: forest, Red: burned area) composites (MIR, NIR and red) of Landsat5 TM images are used here.

\subsection{2 the Yellowstone National Park}

Yellowstone National Park (the YSP) is a natural reserve in northwest Wyoming, USA. Forests cover about $80 \%$ of the total area in the park. The climate is generally cool and dry with mean annual temperature of $4.56^{\circ} \mathrm{C}$, and mean annual precipitation of $390 \mathrm{~mm}$. The summer in 1988 was the driest since 1886 , with only $36 \%$ of average precipitation (National Park Service, YNP). The forest fire occurred in the YSP (Figure 2) from July 2 to November 2, 1988, and the affected areas accounts for about $36 \%$ of the total area of the YSP according to the National Park Service.

\subsection{Materials and pre-processing}

\subsubsection{GLASS-LAI data}

The LAI retrieval algorithm integrated into the GLASS system employs General Regression Neural Networks (GRNNs) to generate a long time series of global LAI data with spatial and temporal continuity from time series of remote sensing observations (MODIS LAI products, VEGETATION LAI products, MODIS and AVHRR surface reflectance data). cording to the extensive verification results of GLASS LAI products for different vegetation types, GLASS LAI products are spatially complete, smooth and continuous in time, and their product accuracy is better than that of MODIS and CYCLOPES LAI products.

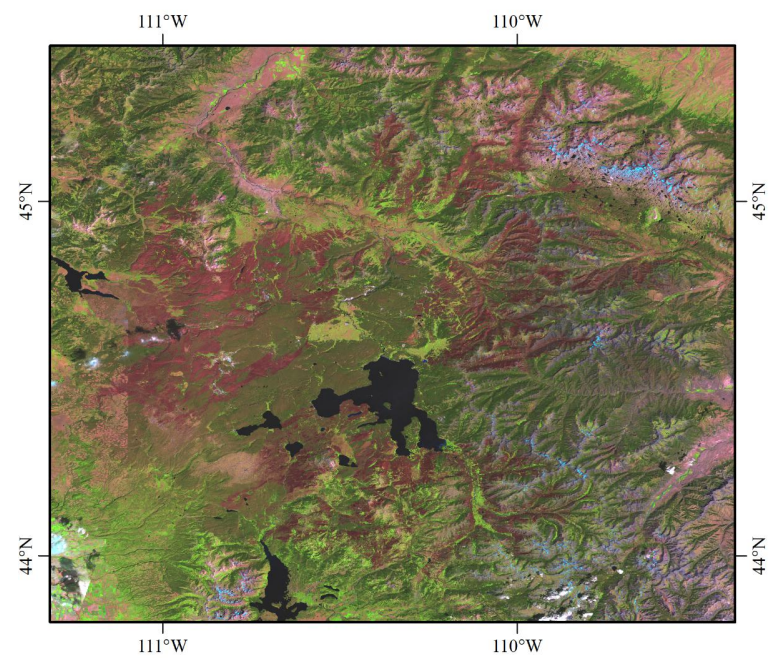

Figure 2: Study area and image of post-fire in the Yellowstone National Park. False color (Green: forest, Red: burned area) composites (MIR, NIR and red) of Landsat5 TM images are used here.

The LAI data from 1981 to 2016 downloaded from the datasharing platform of Beijing Normal University (http://glassproduct.bnu.edu.cn/) in the study area of the GKM and the YSP with the time resolution of $8-$ day and spatial resolution of $1 \mathrm{~km} \times 1 \mathrm{~km}$. And the valid value of LAI data was calculated used the scale factor of 0.1 and the invalid value (255) was eliminated

\subsubsection{Landsat 5-TM data}

This paper used the landsat5TM data pre and post fire to extract forest fire extent, and calculates the burn severity in burned area, which downloaded from the US Geological Survey (USGS) (http://earthexplorer.usgs.gov). The Path/Row, data acquisition time as shown in Table 1. Landsat data pre-processing based on ENVI contains radiometric calibration, atmospheric correction, and study area clip. The surface reflectance of each band was calculated used the radiation calibration parameters showed in the header file of the Landsat data.

\begin{tabular}{|c|r|r|c|c|}
\hline \multirow{2}{*}{ Study area } & \multirow{2}{*}{ row } & path & \multicolumn{2}{|c|}{ Date (Year/Month/Day) } \\
\cline { 5 - 6 } & & & Pre-fire & Post-fire \\
\hline \multirow{2}{*}{ GKM } & $22-$ & $120-$ & $1986 / 06 / 03-1986 / 08 / 08$ & $\begin{array}{c}1987 / 06 / 06- \\
1987 / 09 / 26\end{array}$ \\
& 24 & 123 & & $1989 / 08 / 02-$ \\
& $28-$ & $37-$ & $1987 / 08 / 05-1987 / 09 / 06$ & $198909 / 04$ \\
\hline \multirow{2}{*}{ YSP } & 30 & 39 & &
\end{tabular}

Table 1: Landsat 5 - TM data used in this paper

\subsubsection{MODIS land cover type data product (MCD12Q1)}

We used MODIS land cover type data product (MCD12Q1) with IGBP classification system from $2000-2013$ to analyse the succession of different vegetation types after fire in burned area. The data downloaded from the NASA Space Agency MODIS Land Download Center (http://modisland.gsfc.nasa.gov) with a spatial resolution of $500 \mathrm{~m}$. Data preprocessing includes projection conversion, format conversion, and study area clip. We used MRT (MODIS Reprojection Tool) tool converted the projection of MODIS12Q1 data from sinusoidal projection (ISIN) to Albert, the data format from .hdf to .tif. 


\subsection{Methodology}

\subsubsection{Burn Severity Calculation}

Burn severity of the GKM and the YSP are detected based on the differenced Normalized Burn Ratio (dNBR) calculated by the band4/7 of landsat5 TM image data. dNBR is calculated as follows:

$$
\begin{gathered}
\mathrm{d} N B R=N B R \text { pre }-N B R \text { post } \\
N B R=\left(\rho_{4}-\rho_{7}\right) /\left(\rho_{4}+\rho_{7}\right)
\end{gathered}
$$

Where, NBRpre, NBRpost is the NBR value of pre and postfire respectively, and the NBR is calculated by the reflectance of near infrared band ( $\rho 4)$ and mid-infrared band $(\rho 7)$. The burned area was extracted if dNBR $\geqslant 0.3$ (Li 2017, Yu 2015), and the dNBR in the high and low burn severity areas range from $0.5-2$ and 0.3-0.5 respectively. And this paper selected the sample area with different burn severity to analyse the disturbance of LAI. The location of the sample area and the burn severity in the GKM and the YSP showed in Figure 3 and Figure 4, respectively.

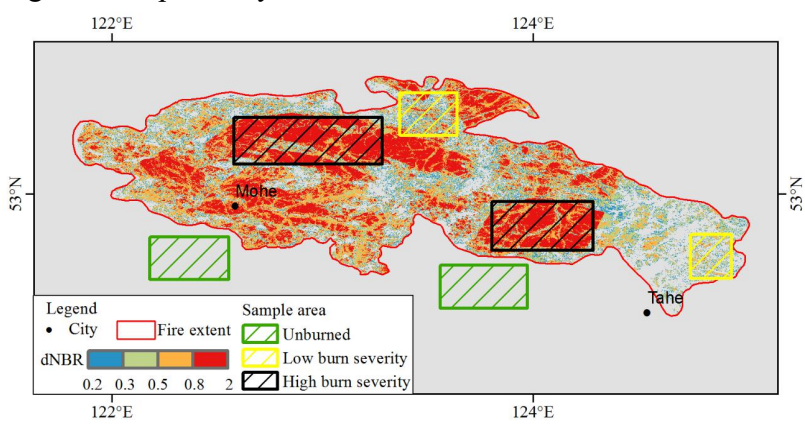

Figure 3: Burn severity and the location of the sample area in the Greater Khingan Mountains.

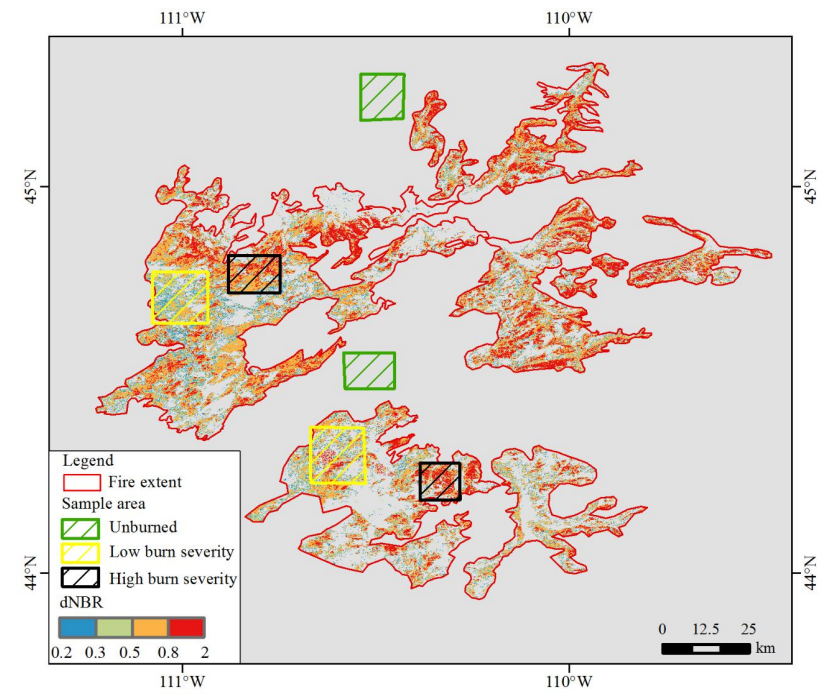

Figure 4: Burn severity and the location of the sample area in the Yellowstone National Park.

\subsubsection{Anomaly Analysis}

Based on the inter-annual variation of LAI of forest land in the GKM and YSP (as shown in Figure 5), it can be seen that the LAI rise first and then fall with the maximum value in July. We calculated the anomaly value of LAI to analyse the disturbance of forest vegetation. Monthly LAI was calculated by averaging the 8-day LAI and annual LAI was calculated by maximizing the monthly LAI (MVC), MVC can maximize the elimination of noise and errors caused by cloud, rain, snow, etc (Yin 2015). The anomaly of LAI of pixel i in study area was calculated as follows:

$$
\mathrm{VI}_{\mathrm{i}}^{\mathrm{t}^{\prime}}=\mathrm{VI}_{\mathrm{i}}^{\mathrm{t}}-\mathrm{VI}_{\mathrm{i}}
$$

Where, $\mathrm{VI}_{\mathrm{i}}^{\mathrm{t}^{\prime}}$ is the anomaly value of LAI of pixel $\mathrm{i}$ in time t, $\mathrm{VI}_{\mathrm{i}}^{\mathrm{t}}$ is the value of LAI of pixel $\mathrm{i}$ in time $t, \mathrm{VI}_{\mathrm{i}}$ is the mean LAI of pixel i over the period of 1981-2016.

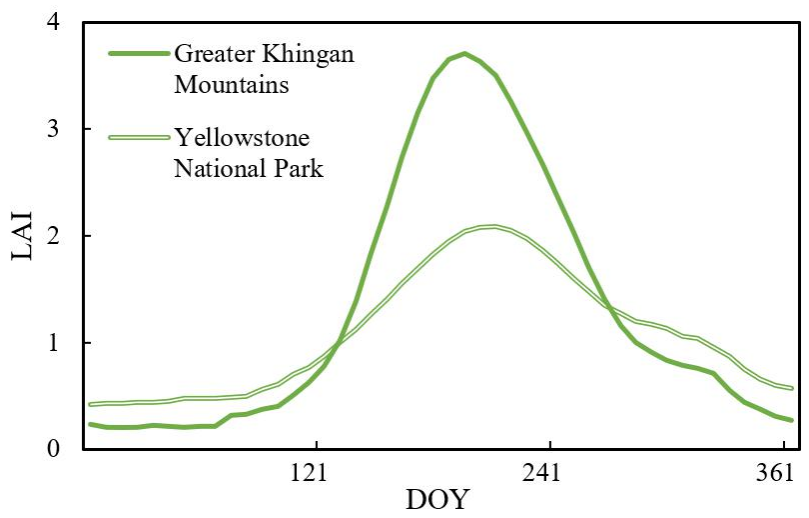

Figure 5: The changes of LAI during the year in unburned area in the Greater Khingan Mountains and the Yellowstone national Park.

\section{RESULTS AND DISCUSSION}

\subsection{Spatial Analysis of the Anomaly of LAI}

The Distribution of the anomaly of LAI in the GKM and its surrounding areas (Figure 6) showed that the anomaly of LAI in burned areas in 1987 was negative and the deviation was the highest $(-3.6--2)$, the proportion of pixels with negative the anomaly of LAI was $99.7 \%$ in $1987,96.3 \%$ in $1992,82.5 \%$ in 1997 and $8.7 \%$ in 2002, respectively (Figure 7); The anomaly of LAI in burned area was lower than that in the surrounding unburned area every year. The difference of the anomaly of LAI between the burned area and unburned area was decreasing with time going. The averaged difference of the anomaly of LAI was 2.0 - 2.6 in 1987; The proportion of pixels with the difference of the anomaly of LAI ranging from 2.0 to 2.6 was significantly decreased in 1992 and the distribution of lower the anomaly of LAI in 1992 was highly consistent with the distribution of the high burn severity; And there are a small number of the high burn severity pixels with the anomaly of LAI difference about 1.0 in 1999 .

The Distribution of the anomaly of LAI in the YSP and its surrounding areas (Figure 8) showed that the lowest the anomaly of LAI $(-1.7--1.0)$ in burned area was in 1989 rather than 1988 because the fire in the YSP occurred after the growing season, and the proportion of pixels with negative the anomaly of LAI was $90.1 \%$ in $1989,76.7 \%$ in $1994,64.0 \%$ in 1999 and $32.0 \%$ in 2004, respectively (Figure 9); The difference of the anomaly of LAI between the burned area and unburned area in the YSP was smaller compared with that in the 
GKM because the summer in the YSP in 1988 was the driest on record.
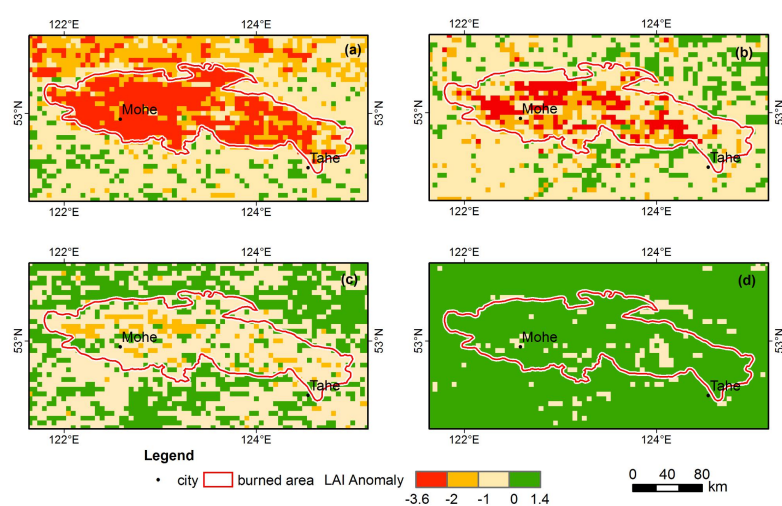

Figure 6: The Distribution of the anomoly of LAI in the Greater Khingan Mountains. (a) 1987. (b) 1992. (c) 1997. (d) 2002.

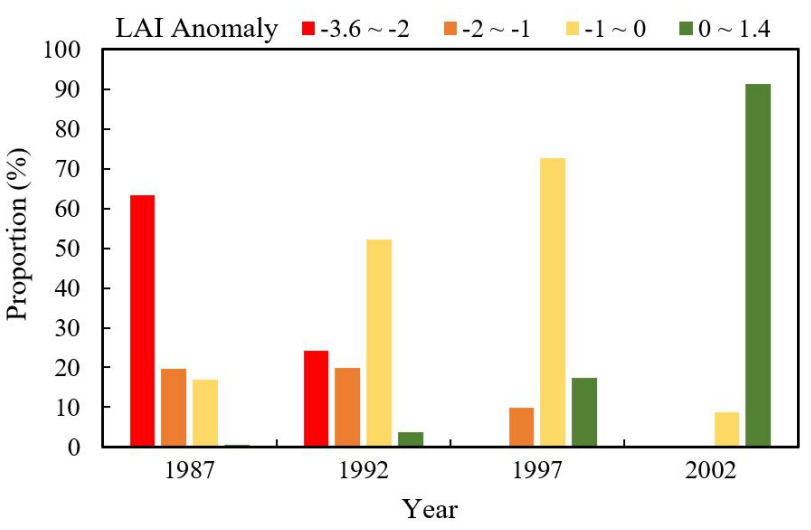

Figure 7: Anomoly changes of LAI in burned area in the Greater Khingan Mountains
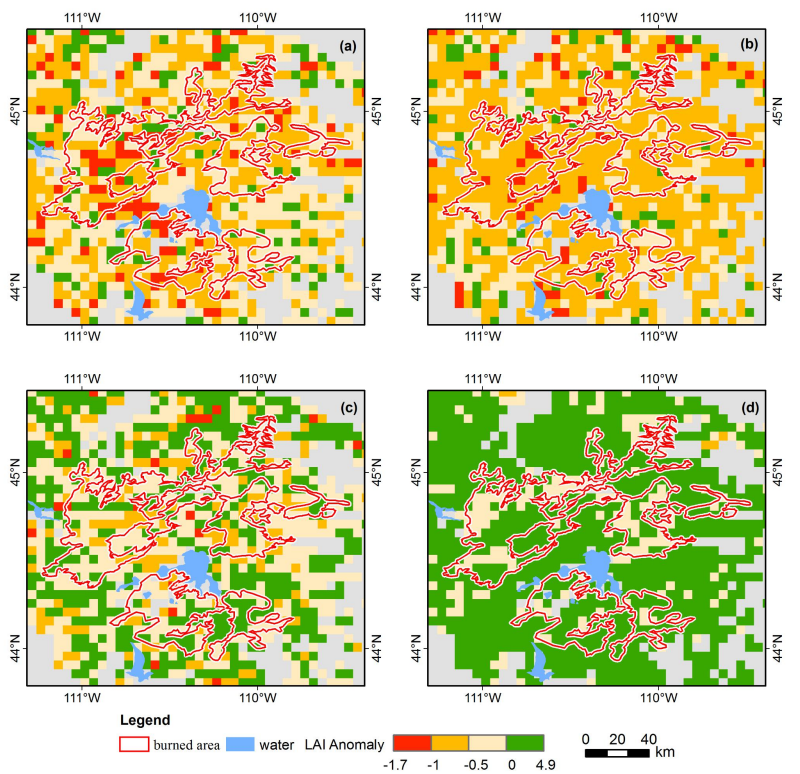

Figure 8: The Distribution of the anomoly of LAI in the Yellowstone National Park. (a) 1987. (b) 1992. (c) 1997. (d) 2002.

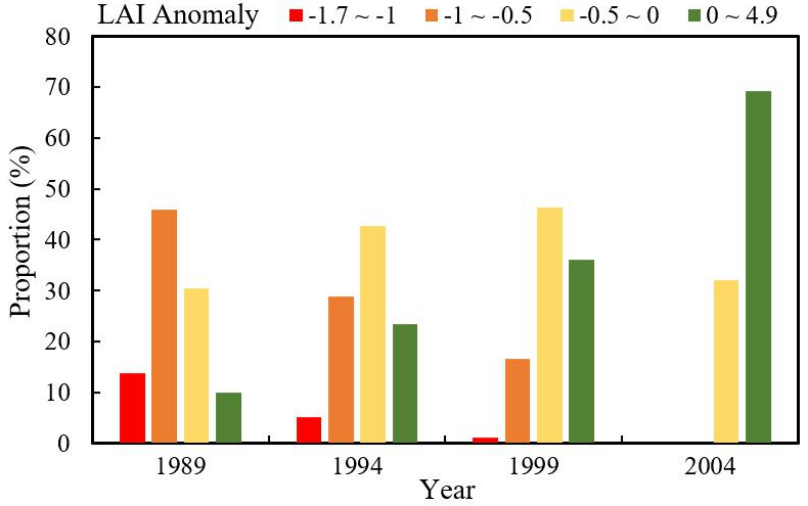

Figure 9: Anomoly changes of LAI in burned area in the Yellowstone National Park.

\subsection{Analysis of the Change of LAI}

The analysis of the change of LAI in the different burn severity area and unburned area in the GKM (Figure 10) and the YSP (Figure 11) showed that the LAI in burned area decreased rapidly after the fire and then increased to normal slowly. The higher the burn severity, the higher the decreasing amplitude and the longer the recovery time. The maximum decreasing amplitude of LAI in the high burn severity areas in the GKM and the YSP was 1.6, 3.8 times larger than that in the low burn intensity areas, respectively. The LAI recovery time in the high burn severity areas was about 2 times longer than that in the low burn severity area in the GKM. F. J. Jie' s study also showed that the higher the burn severity, the worse the vegetation recovery (Xie 2005).

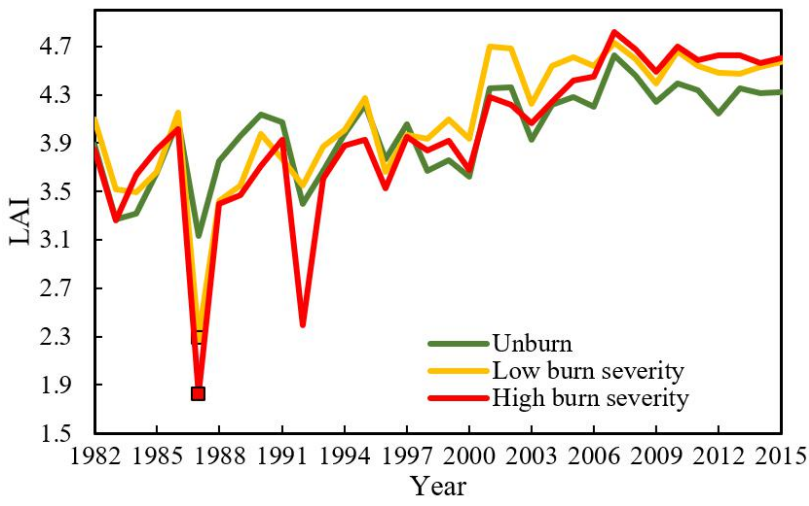

Figure10: The change of LAI in the different burn severity area and unburned area in the Greater Khingan Mountains.

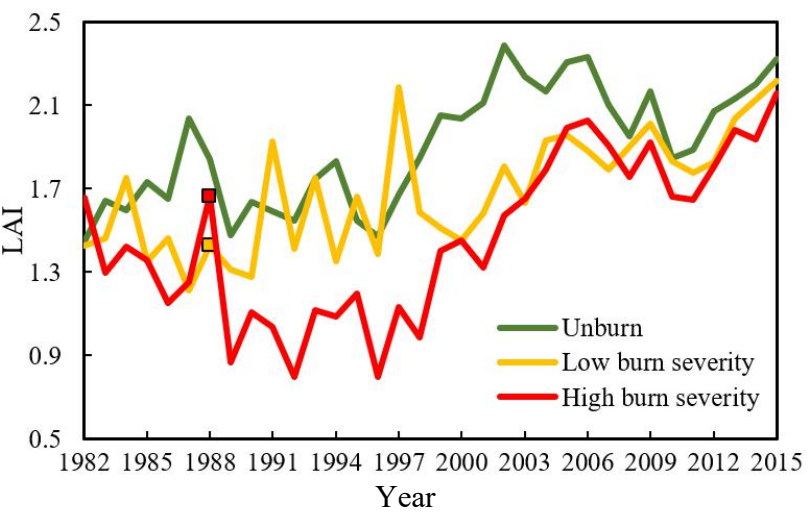

Figure 11: The change of LAI in the different burn severity area and unburned area in the Yellowstone National Park. 
The LAI in the high burn severity area in the GKM in 1992 was decreased because of the forest fire in this year, and the LAI in burned areas was higher than that in unburned areas after 2003, which was proved by $\mathrm{X}$. G. Wang, et al: the main vegetation type in the GKM was birch, mixed with a certain of larch after 2003 (Wang 2003). The distribution of burned area in the GKM was concentrated and the area was large, and the LAI recovery time in the low and high burn severity areas in the GKM was 5 and 10 years, respectively.

The LAI in burned areas in the YSP maintained low level in 13 years after fire, and the LAI recovery time in the low burn severity areas in the YSP was 20 years while the vegetation in the high severity burned area takes longer time to recovery.

\subsection{Land Cover Change in Burned Area}

The analysis of vegetation succession in the GKM (Figure 12) and the YSP (Figure 13) after the fire based on MDC12Q1 data showed that:

3.3.1 The proportion of forest in burned areas in the GKM (mainly with mixed forest, deciduous needleleaf forest and deciduous broadleaf forest) was highest, and expanded gradually (from $74.51 \%$ to $87.53 \%$ ); The proportion of cropland/Natural vegetation mosaic decreased from $19.25 \%$ to $5.45 \%$, and it was mainly distributed in the high burn severity areas. The proportion of forest increased rapidly and proportion of cropland/Natural vegetation mosaic decreased rapidly in 2004. The proportion of different vegetation types was stable in 2007, and the proportion of forest was largest in 2009. Wang L $\mathrm{H}$, et al proved that the Margalef richness and Shannon-Wiener was the highest in 2009 (Wang 2015).

3.3.2 From 2000 to 2013, the proportion of grasslands decreased from $61.74 \%$ to $45.57 \%$, while the proportion of forest (mainly with evergreen needleleaf forest and evergreen broadleaf forest) increased from $6.35 \%$ to $51.16 \%$ in the YSP. In addition, the proportion of different vegetation types fluctuated greatly in 2009. In general, the forest is expanding gradually.
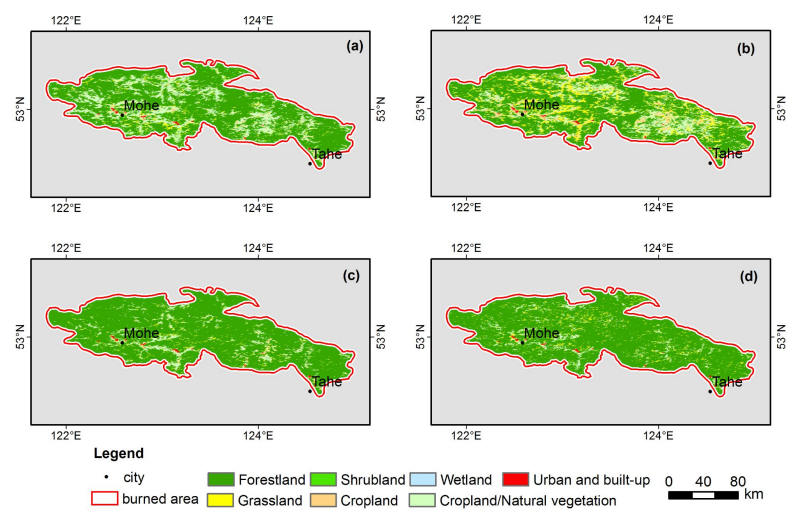

Figure 12: The succession of vegetation after forest fire in the Greater Khingan Mountains
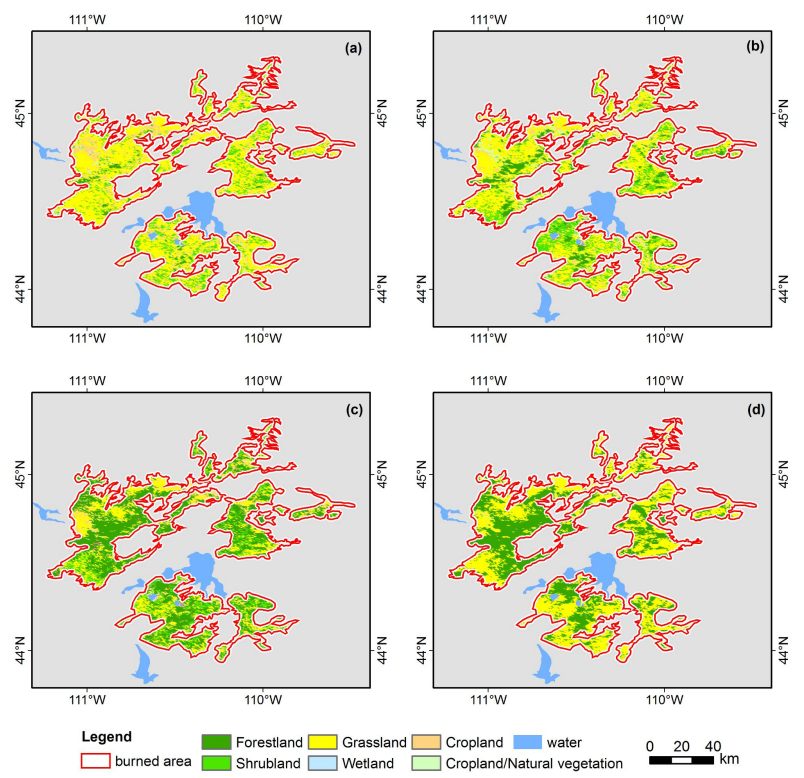

Figure 13. The succession of vegetation after forest fire in the Yellowstone National Park.

\subsection{The Effect of Different Measures on the Recovery of Burned Forest}

The fire in the GKM with burned area of 133 million $\mathrm{hm} 2$. After the fire, the GKM Forestry Bureau has formulated the implementation plan of the forest resource restoration project, cleaned up the burned wood timely manner, adopted artificial recovery project in local areas to promote the regeneration of forest in burned area. However, The Yellowstone National Park, which is an important nature reserve, only measures natural recovery measures. As a result, The LAI in burned area in the GKM after forest fire decreased rapidly then increased rapidly. The LAI recovery time in the low and high burn severity areas was 5 and 10 years, respectively. In addition, the proportion of different vegetation types reaches the stable level in 21 years after the fire. However, The LAI in burned area in the YSP after forest fire decreased rapidly and maintained low level in 13 years after fire, then increased slowly. The LAI recovery time in the low burn severity areas was 20 years, respectively. In addition, the proportion of different vegetation types reaches the stable level more than 25 years after the fire. Therefore, we can get the conclusion that artificial afforestation measures can shorten the LAI recovery time.

\section{CONCLUSIONS}

Three conclusions could be drawn for this research:

(1) The LAI can detect the response and the recovery characteristics of vegetation to forest fire. LAI in burned area decreased rapidly and then increased slowly after fire, and the maximum decreasing amplitude of LAI in the high burn severity areas was $1.3-4.8$ times higher than that in the low burn severity burned areas. The LAI recovery time in the high burn severity areas was about 2 times higher than that in the low burn severity areas in the GKM. And the manual interference can significantly shorten vegetation recovery time.

(2) The recovery of LAI does not mean the recovery of vegetation structure. Forest fires can destroy the forest ecosystem and change the type of vegetation, and the recovery 
of dominant species will take longer time. The LAI recovery time in burned areas in the GKM was 10 years, while the proportion of different vegetation types reaches the stable level in 21 years after the fire. The growth of shrublands of the high burn severity area has a greater contribution to LAI, and the recovery time of forest ecology is much longer than that of LAI.

(3) Different recovery measures have great influence on the process of vegetation recovery after the forest fire. The intervening measures such as clearing over firewood and local artificial afforestation have accelerated the recovery of vegetation of forest and promoted the improvement of forest biomass and carbon sink function after the forest fire in the GKM. The YSP only the use the natural recovery measures. The recovery time of vegetation parameters in Yellowstone National Park is about 2 times longer than that of the GKM area.

There are still some aspects that can be improved and refined in further research. Firstly, the contribution of different vegetation species to LAI should be evaluated to research the recovery of vegetation structure. Secondly, this research only used the leaf area index to evaluated the changes of vegetation in burned areas, and other vegetation indices such as FAPAR (the Fraction of Absorbed Photosynthetically Active Radiation) and Albedo should be used to track the change of vegetation from other aspects.

\section{ACKNOWLEDGEMENTS}

Acknowledgements of support for the project:

(1) National key research and development project: Highprecision multi-source comprehensive drought monitoring and evaluation technology.

(2) Key research and development projects of the state: Research and demonstration of key technologies for integrated monitoring of emergency response for major and major disasters.

(3) National natural science foundation of China: Research on spatial scale reduction model of urban surface temperature based on improved SVM model.

\section{REFERENCES}

Cai, W. H. , 2012. "Controls of post-fire tree recruitment in Great Xing'an Mountains in Heilongjiang Province," Acta Ecologica Sinica, vol. 32, no. 11, pp. 3303-3312.

García-Haro, F. J. , 2001 "Monitoring fire-affected areas using Thematic Mapper data," International Journal of Remote Sensing, vol. 22, no. 4, pp. 533-549.

Gp, H. J. A. , 2003 "Postfire response of North American boreal forest net primary productivity analyzed with satellite observations," Global Change Biology, vol. 9, no. 8, pp. 11451157.

Hernandez, R. C. , 2009 "Monitoring post-fire regeneration in Mediterranean ecosystems by employing multitemporal satellite imagery," International Journal of Wildland Fire, vol. 18, no. 6, pp. $648-658$.

Houghton, R. A. , 1989. "Global climatic change," Scientific American, vol. 4, no. 4, pp. 36-44.

Ichoku, R. A. , 2012 "Satellite contributions to the quantitative characterization of biomass burning for climate modeling," Atmospheric Research, vol. 111, no. 1, pp. 1-28.
Liang, B. Y. , 2016 "Changes in the Amazon rainforest from 1982 to 2012 using GLASS LAI data," Journal of Remote Sensing, vol.20, no.1, pp.149-156.

Liang. S. L. , 2014 "Global land surface satellite (GLASS) products: algorithms, validation and analysis," Higher Education Press.

Li, M. Z. , 2015 "Iner - annual variation in vegetation index and analysis of factors affecting it in Daxing' an Mountaions,"Journal of Beijing Forestry University, vol.37, no.5, pp.1-10.

Li, M. Z. , 2017 "Burned area extraction in Huzhong forests based on remote sensing and the spatial analysis of the burne severity," Scientia Silvae Sinicae, vol.53, no.3, pp.163-174.

Miao, Q. L., 2015 "NDVI recovery process for post-fire vegetation in the Greater Khingan Mountain," Science Silvae Sinicae, vol. 51, no. 2, pp. 90-98.

Shi, P. J., 2015 "World Atlas of Natural Disaster Risk," Springer Berlin Heidelberg, pp. 309-323.

Wang, J. , 2017 "Detecting Forest Disturbance in Northeast China from GLASS LAI Time Series Data Using a Dynamic Model," Remote Sensing, vol.12, no.9.

Wang, L. H. , 2015. "Plants diversity and biomass distribution of vegetation restoration in burned area of Great Xing'an Mountains," Journal of Beijing Forestry University, vol. 37, no.12, pp.41-47.

Wang, M. Y. , 2008 "Advances in post-fire recovery research," World Forestry Research, vol. 21, no. 6, pp. 49-53.

Wang, X. G. , 2003 "Model of vegetation restoration under natural regeneration and human interference in the burned area of northern Daxinganling," Chinese Journal of Ecology, vol. 22, no. 5 , pp. $30-34$.

Xiao, M., 2011 "Recovery of vegetation canopy after severe fire in 2000 at the Black Hills National Forest, South Dakota, USA," Journal of Resources and Ecology, vol.02, no.2, pp.106116.

Xie, F. J. , 2005 "Forest landscape restoration assessment based on NCVI under different burn intensity in the burned blank of Daxinganling Mountains," Chinese Journal of Ecology, vol. 24, no. 4 , pp. $368-372$.

Xie, F. J. , 2015 "Forest landscape restoration assessment based on NCVI under different burn intensity in the burned blank of Daxinganling Mountains," Chinese Journal of Ecology, vol. 24, no. 4 , pp. $90-98$.

Yin, G. F. , 2015 "Study on inversion of Leaf Surface Area Index based on multi - source data," University of Chinese Academy of Sciences.

Yu, C. , 2015 "Estimating biomass burned areas from multispectral dataset detected by multiple-satellite," Spectroscopy and Spectral Analysis, no.3, pp.739-745. 